\title{
The liquefaction and displacement of highly saturated sand under water pressure oscillation
}

\author{
Xiaobing $\mathrm{Lu}^{\mathrm{a}, *}$, Peng $\mathrm{Cui}^{\mathrm{b}}$ \\ a Institute of Mechanics, Chinese Academy of Sciences, 100080 Beijing, China \\ b Institute of Mountain Hazard and Environment, Chinese Academy of Sciences, 610041 Chengdu, China
}

Received 4 April 2003; received in revised form 30 July 2003; accepted 30 October 2003

\begin{abstract}
In order to investigate the characteristics of water wave induced liquefaction in highly saturated sand in vertical direction, a one-dimensional model of highly saturated sand to water pressure oscillation is presented based on the two-phase continuous media theory. The development of the effective stresses and the liquefaction thickness are analyzed. It is shown that water pressure oscillating loading affects liquefaction severely and the developing rate of liquefaction increases with the decreasing of the sand strength or the increasing of the loading strength. It is shown also that there is obvious phase lag in the sand column. If the sand permeability is non-uniform, the pore pressure and the strain rise sharply at which the smallest permeability occurs. This solution may explain why the fracture occurs in the sand column in some conditions.
\end{abstract}

(C) 2004 Elsevier Ltd. All rights reserved.

Keywords: Saturated sand; Liquefaction; Ocean wave; Pore pressure oscillation

\section{Introduction}

In order to study the development of liquefaction either to prevent the liquefaction hazard or to consolidate sand foundations, it is necessary to understand the mechanism of liquefaction. When a wave loading is applied to the sand foundation, liquefaction may occur under some conditions. Liquefied foundation has small strength and so can slide or flow even with a very small slope. Much attention and efforts have been put on shear responses of saturated sand and a series of

\footnotetext{
${ }^{*}$ Corresponding author. Tel.: +86-10-6255-4188.

E-mail address: xblu@imech.ac.cn (X. Lu).
} 


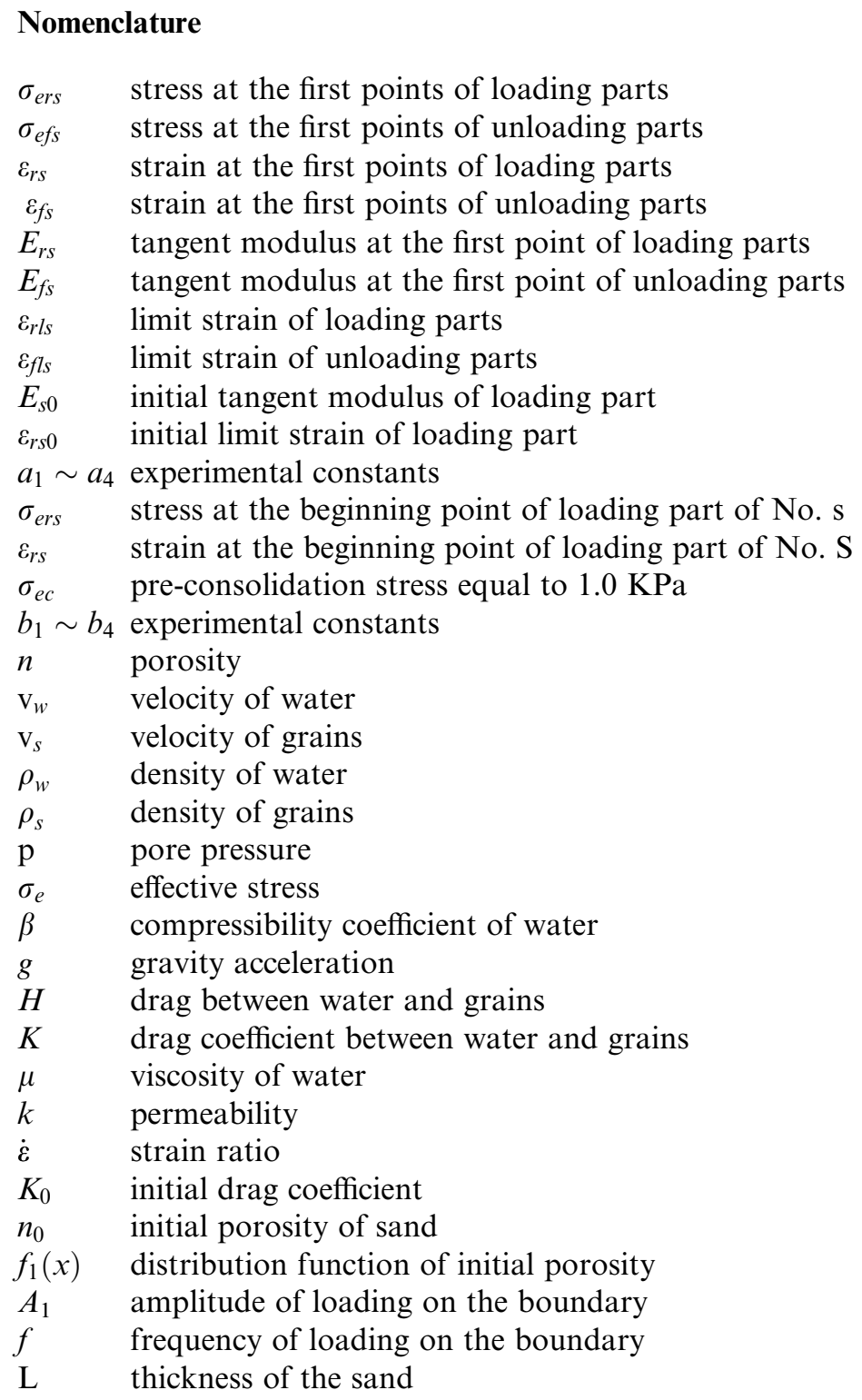

results has been obtained since liquefaction caused by earthquakes is considered to be the result of shear (Finn et al., 1977; Liou and Streeter, 1977). Some work has been done about wave propagating and development of pore pressure in saturated sand by considering the coupling of shear loading and vertical loading (Zienkiewicz 


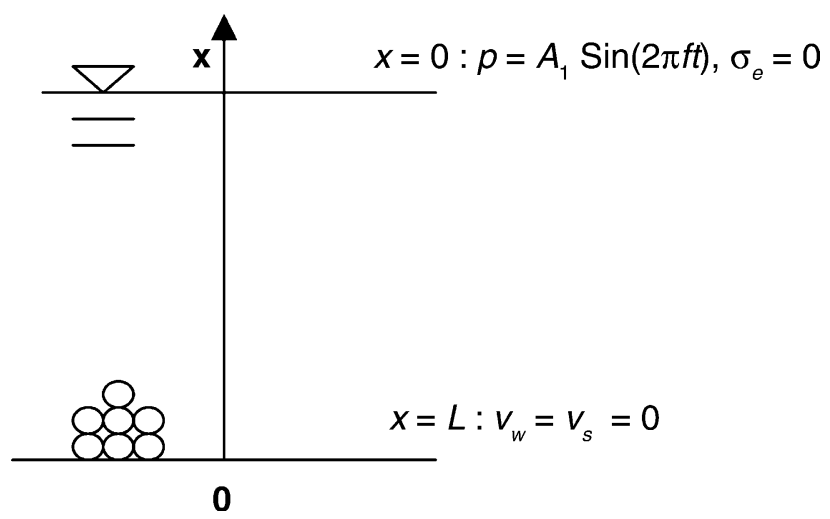

Fig. 1. The sketch of the problem.

and Shiomi, 1984; Provest, 1982). Although these works are helpful in the study of liquefaction, the sustaining pore pressure is thought to be caused by shear only. Recently, some results on liquefaction of seabed under laterally-confined conditions have been obtained (Zen and Yamazaki, 1990; Nogo and Maeno, 1987; Hideo et al., 1995). Nevertheless, the skeleton of sands is often taken to be elastic and the discussion is much about the development of pore pressure or effective stress.

In the present paper, we discuss the characteristics of the development of the effective stresses and the liquefaction thickness and the nonuniform displacements of a highly saturated sand layer under water pressure oscillation by a one-dimensional model (Fig. 1).

\section{The basic equations}

\subsection{The constitutive relation}

The side-constrained constitutive relation is adopted ( $\mathrm{Lu}, 1999)$ which is consisted of loading part and unloading part and the data are obtained from experiments.

The expression of constitutive relation is shown as follows

$$
\begin{aligned}
& \text { The loading part : } \sigma_{e}-\sigma_{e r s}=\frac{E_{r s}\left(\varepsilon-\varepsilon_{r s}\right)}{1+\frac{\varepsilon-\varepsilon_{r s}}{\varepsilon_{r l s}}} \\
& \text { The unloading part : } \sigma_{e}-\sigma_{e f s}=\frac{E_{f s}\left(\varepsilon-\varepsilon_{f s}\right)}{1+\frac{\varepsilon-\varepsilon_{f s}}{\varepsilon_{f l s}}}
\end{aligned}
$$

in which $\sigma_{e r s}, \sigma_{e f s}, \varepsilon_{r s} \varepsilon_{f s}$ are respectively the stresses and the strains at the first points of loading parts and unloading parts, $E_{r s}, E_{f s}, \varepsilon_{r l s}, \varepsilon_{f l s}$ are, respectively, the 
tangent modulus and limit strains of loading parts and unloading parts. They are decided by the following equations.

The change roles of parameters of loading parts are

$$
\begin{aligned}
& E_{r s}=E_{r 0}\left(1+\frac{\varepsilon_{r s}}{a_{1}+a_{2} \varepsilon_{r s}}\right)\left(1+\frac{\sigma_{e r s}}{\sigma_{e c}}\right)^{0.5} \\
& \varepsilon_{s r}=\varepsilon_{r l 0}\left(1-\frac{\varepsilon_{r}}{a_{3}+a_{4} \varepsilon_{r}}\right)\left(1+\frac{\sigma_{e r}}{\sigma_{e c}}\right)^{0.5}
\end{aligned}
$$

in which $E_{s 0}, \varepsilon_{r s 0}$ are, respectively, the initial tangent modulus and limit strain of loading part, $a_{1} \sim a_{4}$ are experimental constants, $\varepsilon_{r s}, \sigma_{e r s}$ are respectively the stress and the strain of the beginning point of loading part of No. s, $\sigma_{e c}$ is the pre-consolidation stress and is equal to $1.0 \mathrm{KPa}$.

The changed roles of parameters of unloading parts are

$$
\begin{aligned}
& E_{f s}=E_{r 0}\left(1+\frac{\varepsilon_{f s}}{b_{1}+b_{2} \varepsilon_{f s}}\right)\left(1+\frac{\sigma_{e f s}}{\sigma_{e c}}\right)^{0.5} \\
& \varepsilon_{f l s}=\varepsilon_{r l 0}\left(1-\frac{\varepsilon_{f s}}{b_{3}+b_{4} \varepsilon_{f s}}\right)\left(1+\frac{\sigma_{e f s}}{\sigma_{e c}}\right)^{0.5}
\end{aligned}
$$

in which $b_{1} \sim b_{4}$ are experimental constants. The sketch of the constitutive relation and the variables and the examples of experiments are shown in Fig. 2.

\subsection{The equilibrium equations and the initial and boundary conditions}

The governing equations of saturated sand were first established for dynamic phenomenon by Biot (1956) and some analytical results were given (Biot, 1962) afterwards. At a later date, governing equations based on mixture theory were proposed (Green and Naghdi, 1965; Green, 1970), but the rederivation of the equations was achieved with no substantial or rational changes from Biot's equations. Owing to increasing interest in nonlinear applications, a generalized incremental form was derived by Zienkiewicz et al. (1980) and Provest (1980, 1982). In our discussion, one-dimensional controlling equations of highly saturated sand assuming water is compressible is adopted based on two phase mixture theory ( $\mathrm{Yu}, 1988)$ :

$$
\left\{\begin{array}{l}
n \beta \frac{\partial p}{\partial t}+\rho_{w} \frac{\partial n}{\partial t}+n \rho_{w} \frac{\partial v_{w}}{\partial x}+\rho_{w} v_{w} \frac{\partial n}{\partial x}+n v_{w} \beta \frac{\partial p}{\partial x}=0 \\
\frac{\partial n}{\partial t}-(1-n) \cdot \frac{\partial v_{s}}{\partial x}+v_{s} \cdot \frac{\partial n}{\partial x}=0 \\
n \rho_{w} \cdot \frac{\partial v_{w}}{\partial t}+n \frac{\partial p}{\partial x}=-H+n \rho_{w} g \\
(1-n) \cdot \rho_{s} \cdot \frac{\partial v_{s}}{\partial t}+(1-n) \cdot \frac{\partial p}{\partial x}+\frac{\partial \sigma_{e}}{\partial x}=H+(1-n) \rho_{s} g
\end{array}\right.
$$

in which $n$ is the porosity, $\mathrm{v}_{w}, \mathrm{v}_{s}$ are respectively the velocities of water and grains, $\rho_{w}$ is the density of water, $\rho_{s}$ is the density of.grains, $p$ is the pore pressure, $\sigma_{e}$ is the effective stress, $\beta$ is the compressibility coefficient of water, $g$ is the gravity 

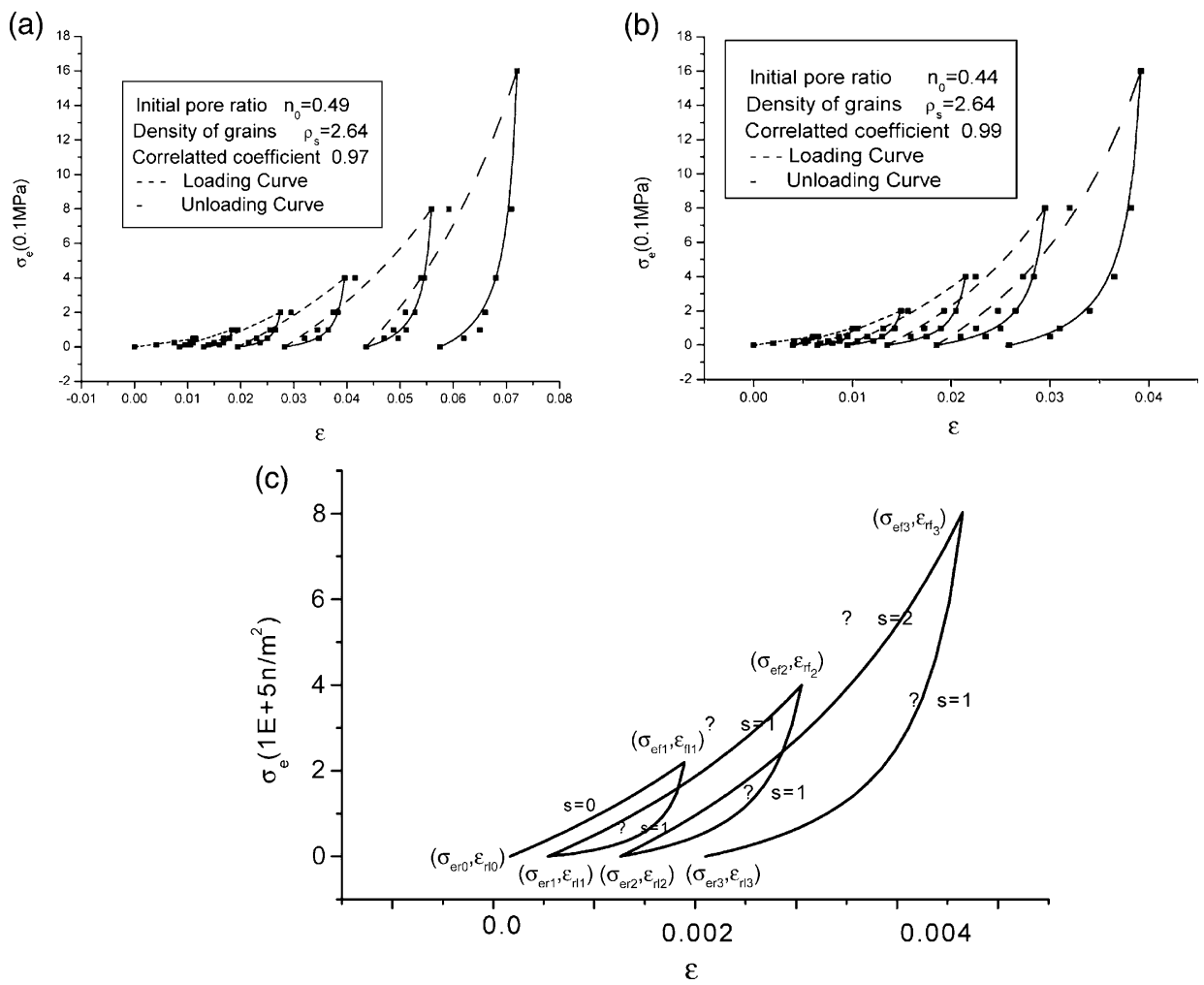

Fig. 2. The sketch of the constitutive relation and examples of experiments. (a) Comparing of experimental data and fitted data of sample no. 1; (b) Comparison of experimental data and fitted data of sample no. 2; (c) The sketch of the constitutive relation and the variables.

acceleration, $H$ is the drag between water and grains and is assumed as

$$
H=n^{2}\left(\mathrm{v}_{w}-\mathrm{v}_{s}\right) / K
$$

in which $K$ is the drag coefficient between water and grains and $K=k / \mu, \mu$ is the viscosity of water, $k$ is the permeability and

$$
\begin{aligned}
& \dot{\varepsilon}=\frac{\partial v_{s}}{\partial x} \\
& K=\left(\frac{n}{n_{0}}\right)^{5}\left(\frac{1-n_{0}}{1-n}\right)^{2} K_{0}
\end{aligned}
$$

in which $K_{0}$ is the initial drag coefficient when the initial porosity of sand is $n_{0}$ (Huang, 1983). 
The initial conditions are

$$
t=0, n=f_{1}(x), \quad p=\rho_{w} g \cdot x, \quad \sigma_{e}=\left(1-n_{0}\right)\left(\rho_{s}-\rho_{w}\right) g \cdot x, \quad v_{w}=v_{s}=0
$$

in which $f_{1}(x)$ is the distribution function of initial porosity.

The boundary conditions are

$$
\left\{\begin{array}{l}
x=0, \quad p=A_{1} \sin (2 \pi f t), \quad \sigma_{e}=0 \\
x=L, \quad v_{s}=v_{s}=0
\end{array}\right.
$$

in which $A_{1}, f$ are the amplitude and the frequency of loading on the boundary, $L$ is the thickness of the sand layer.

Now, a one-order difference scheme is adopted to obtain the numerical solution. The difference scheme adopted is as follows:

$$
\frac{\partial f}{\partial t}=\frac{f_{i}^{j}-f_{i}^{j-1}}{\Delta t}, \quad \frac{\partial f}{\partial x}=\frac{f_{i}^{j}-f_{i-1}^{j}}{\Delta x}
$$

Then, the difference schemes of the equilibrium functions are as follows

$$
\left\{\begin{array}{l}
n_{i}^{j} \beta\left(p_{i}^{j}-p_{i}^{j-1}\right)+\rho_{w i}^{j}\left(n_{i}^{j}-n_{i}^{j-1}\right)+\rho_{w i}^{j} n_{i}^{j}\left(v_{w i}^{j}-v_{w i-1}^{j}\right) \frac{\Delta t}{\Delta x} \\
\quad+\rho_{w i}^{j} v_{w i}^{j}\left(n_{i}^{j}-n_{i-1}^{j}\right) \frac{\Delta t}{\Delta x}+n_{i}^{j} v_{w i}^{j} \beta\left(p_{i}^{j}-p_{i-1}^{j}\right) \frac{\mathrm{A} t}{\Delta x}=0 \\
n_{i}^{j}-\left(1-n_{i}^{j}\right)\left(v_{s i}^{j}-v_{s i-1}^{j}\right) \frac{\Delta t}{\Delta x}+v_{s i}^{j}\left(n_{i}^{j}-n_{i-1}^{j}\right) \frac{\Delta t}{\Delta x}=n_{i}^{j-1} \\
\left(\rho_{w}+K_{i}^{j} \Delta t n_{i}^{j}\right) \mathrm{v}_{w i}^{j}-K \Delta t n_{i}^{j} \mathrm{v}_{s i}^{j}+\frac{\Delta t}{\Delta x} p_{i}^{j}-\frac{\Delta t}{\Delta x} p_{i-1}^{j}=\rho_{w} \mathrm{v}_{w i}^{j-1}+\rho_{w} g \\
{\left[1-n_{i}^{j}+K\left(n_{i}^{j}\right)^{2}\right] \mathrm{v}_{s i}^{j}-K \Delta t\left(n_{i}^{j}\right)^{2} \mathrm{v}_{w i}^{j}+\frac{\Delta t\left(1-n_{i}^{j}\right)}{\Delta x} p_{i}^{j}-\frac{\Delta t\left(1-n_{i}^{j}\right)}{\Delta x} p_{i-1}^{j}=D}
\end{array}\right.
$$

in which $i, j$ are, respectively, the space step and the time step, and

$$
\left\{\begin{array}{l}
D=K\left(1-n_{i}^{j}\right) \mathrm{v}_{s i}^{j}+\frac{\sigma_{e i-1}^{j}-\sigma_{e i}^{j}}{\Delta x}+\left(1-n_{i}^{j}\right) g \\
\rho_{w i}^{j}=\beta\left(p_{i}^{j}-p_{i}^{0}\right)+\rho_{w 0}
\end{array}\right.
$$

The difference schemes of the geometry relationship between velocity $v_{s}$ and strain ratio $\dot{\varepsilon}$ is

$$
\begin{aligned}
& \dot{\varepsilon}_{i}^{j-1}=\left(\mathrm{v}_{s i}^{j-1}-\mathrm{v}_{s i-1}^{j-1}\right) / \Delta x \\
& \varepsilon_{i}^{j}=\varepsilon_{i}^{j-1}+\dot{\varepsilon} \Delta t
\end{aligned}
$$


The difference schemes of the relationship of the drag coefficient $K$ and porosity $n$ is

$$
K_{i}^{j}=\left(\frac{n_{i}^{j}}{n_{0}}\right)^{5}\left(\frac{1-n_{0}}{1-n_{i}^{j}}\right)^{2} K_{0}
$$

The difference scheme of loading part:

$$
\sigma_{e i}^{j}-\sigma_{e r s i}^{j}=\frac{E_{r s i}^{j}\left(\varepsilon_{i}^{j}-\varepsilon_{r s i}^{j}\right)}{1-\frac{\left(\varepsilon_{i}^{j}-\varepsilon_{r s i}^{j}\right)}{\varepsilon_{r l s i}^{j}}}
$$

The difference scheme of unloading part:

$$
\sigma_{e i}^{j}-\sigma_{e f s i}^{j}=\frac{E_{f s i}^{j}\left(\varepsilon_{i}^{j}-\varepsilon_{f s i}^{j}\right)}{1-\frac{\left(\varepsilon_{i}^{j}-\varepsilon_{f s i}^{j}\right)}{\varepsilon_{f l s i}^{j}}}
$$

The difference schemes of the changing rules of parameters of loading part

$$
\begin{aligned}
& E_{r s i}^{j}=E_{r 0 i}^{j}\left(1+\frac{\varepsilon_{r s i}^{j}}{a_{1}+a_{2} \varepsilon_{r s i}^{j}}\right)\left(1+\frac{\sigma_{e r s i}^{j}}{\sigma_{e c}}\right)^{0.5} \\
& \varepsilon_{r l s i}^{j}=\varepsilon_{r l 0 i}^{j}\left(1+\frac{\varepsilon_{r s i}^{j}}{a_{3}+a_{4} \varepsilon_{r s i}^{j}}\right)\left(1+\frac{\sigma_{e r s i}^{j}}{\sigma_{e c}}\right)^{j}
\end{aligned}
$$

The difference schemes of the changing rules of parameters of unloading part

$$
\begin{aligned}
& E_{f s i}^{j}=E_{r 0 i}^{j}\left(1+\frac{\varepsilon_{f s i}^{j}}{b_{1}+b_{2} \varepsilon_{f s i}^{j}}\right)\left(1+\frac{\sigma_{e f s i}^{j}}{\sigma_{e c}}\right)^{0.5} \\
& \varepsilon_{r s u l i}^{j}=\varepsilon_{r u l s 0}\left(1+\frac{\varepsilon_{v i}^{j}}{b_{3}+b_{4} \varepsilon_{v i}^{j}}\right)\left(1+\frac{\sigma_{e r i}^{j}}{\sigma_{e c}}\right)^{j}
\end{aligned}
$$

The difference schemes of the initial conditions are

$$
\begin{aligned}
& j=0, n_{i}^{j}=f_{1 i}^{j}(x), p_{i}^{j}=\rho_{w} g \cdot x_{i}, \quad \sigma_{e i}=\left(1-n_{0}\right)\left(\rho_{s}-\rho_{w}\right) g \cdot x_{i}, \\
& \mathrm{v}_{w i}^{j}=\mathrm{v}_{s i}^{j}=0
\end{aligned}
$$

The difference schemes of the boundary conditions are

$$
\begin{aligned}
& i=0, \quad p_{i}^{j}=A_{2} \sin (2 \pi f \cdot j \cdot \Delta t), \quad \sigma_{e i}^{j}=0 \\
& i \rightarrow L, \quad \mathrm{v}_{s i}^{j}=0, \quad \mathrm{v}_{w i}^{j}=0
\end{aligned}
$$




\section{The comparison of development of pore pressure}

Nogo and Maeno (1987) have designed a one-dimensional side-constrained experiment to study liquefaction of the seabed under waves. Vertical vibration is applied on the top of the sand layer through water. The bottom is fixed. The inner diameter of the column is $8.9 \mathrm{~cm}$, while the height is $2.1 \mathrm{~m}$. The parameters of material and loading are the density of grains $\rho_{s}$, the porosity $n$, the permeability $k$, the thickness of sand $D$, the mean water pressure overhead $h_{0}$ (hydrostatic pressure head), the amplitude of pressure variation in the head $a_{0}$, the frequency of pressure variation $f$. Their values are respectively: $n_{0}=0.4 \quad \rho_{s}=2.65 \times 10^{3} \mathrm{~kg} / \mathrm{m}^{3}$, $f=1.37 \mathrm{~Hz}, a_{0}=40 \mathrm{~cm}, h_{0}=100 \mathrm{~cm}, k=1.5 \times 10^{-11} \mathrm{~m}^{2}, D=100 \mathrm{~cm}$.

We computed this problem by using our model and adopting their parameters. The computing data and the experimental results are shown in Fig. 3. There is generally good agreement between them when the skeleton is also taken as elastic.

\section{The development of effective stress}

The development of effective stress is summarized in this section. The parameters adopted are as follows: the initial tangent modulus $E_{r 0}=0.51 \sim 5.1 \mathrm{MPa}$, the initial limit strain $\varepsilon_{r l 0}=0.1 \sim 0.7$, the initial permeability $5 \times 10^{-11} \sim 5 \times 10^{-12} \mathrm{~m}^{2}$, the initial porosity $n_{0}=0.35 \sim 0.55$, the amplitude of loading $A_{1}=0.2 \sim 1.2 \mathrm{Mpa}$, the frequency of loading $f=1 \sim 20 \mathrm{~Hz}$.

It is shown in Figs. 4-9 that the dropping velocity of effective stress increases with the rising of the initial limit strain or the amplitude or the frequency of loading or the porosity or with the decreasing of the modulus or the permeability. As we all know, if the modulus is small or the initial limit strain or porosity is large or amplitude and frequency of loading is large, the compressible tendency of the

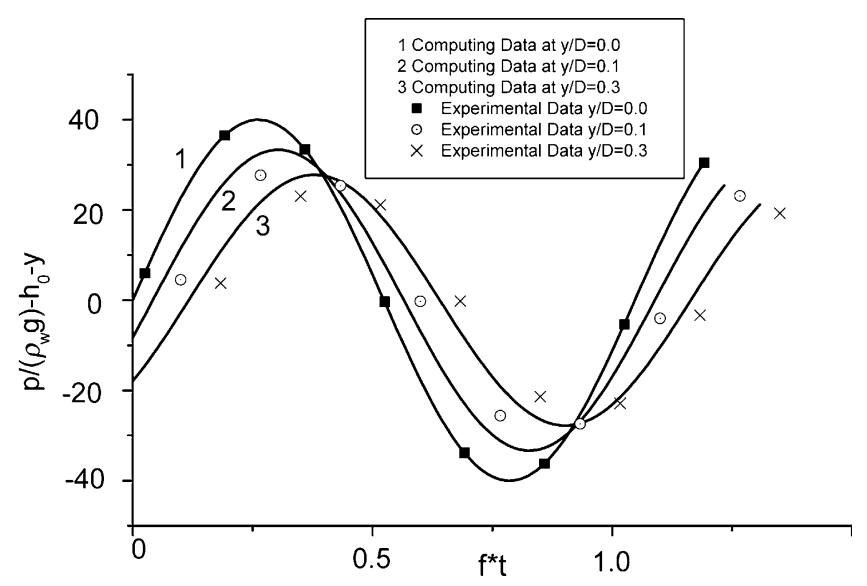

Fig. 3. Comparison of our numerical results and Nogo's results. 


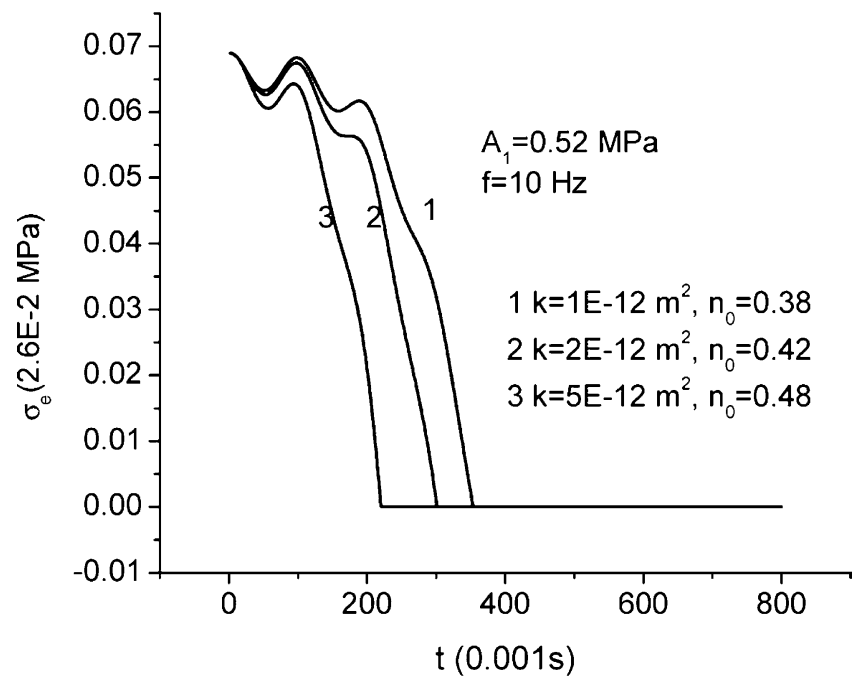

Fig. 4. The influence of the permeability to the effective stress.

skeleton is large, while the permeability is small, the pore water will be difficult to drain and the pore pressure will rise and the effective stress will then drop. Therefore, in order to prevent liquefaction, it is necessary to make sand density or the amplitude and the frequency of loading small.

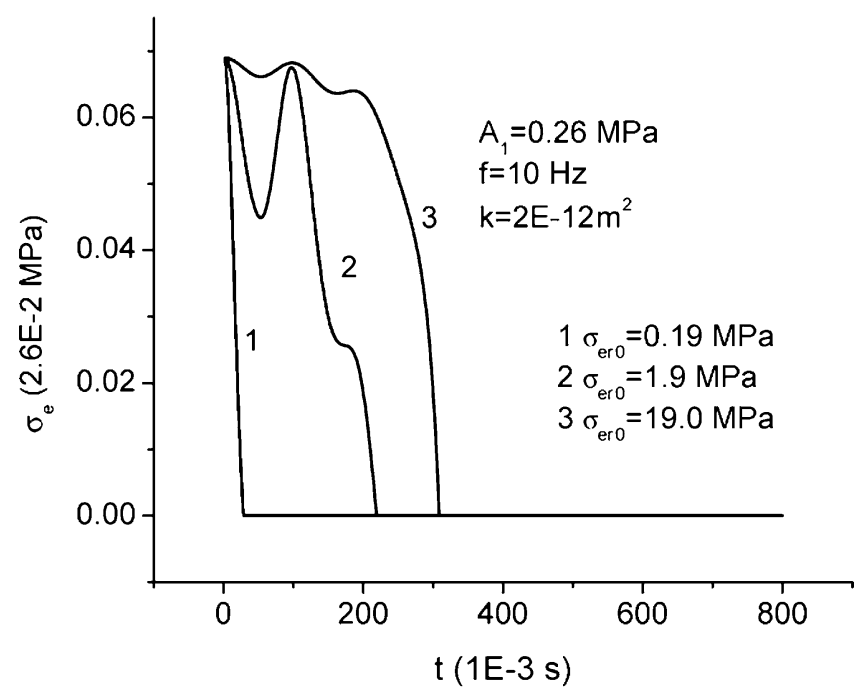

Fig. 5. The influence of initial tangent modulus to the effective stress. 


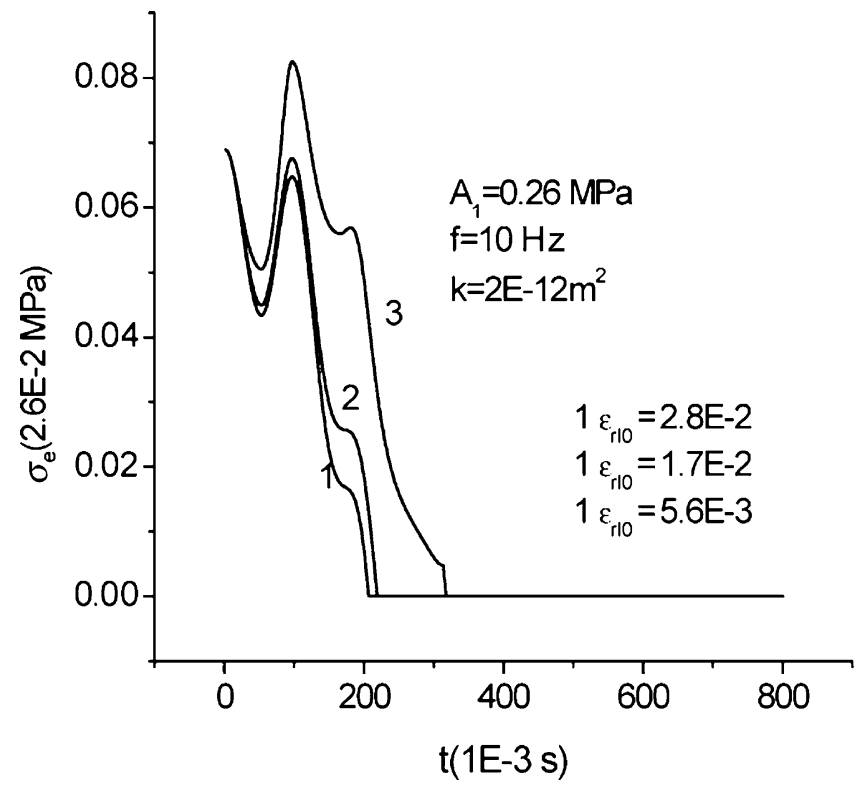

Fig. 6. The influence of initial limit strain of loading to the effective stress.

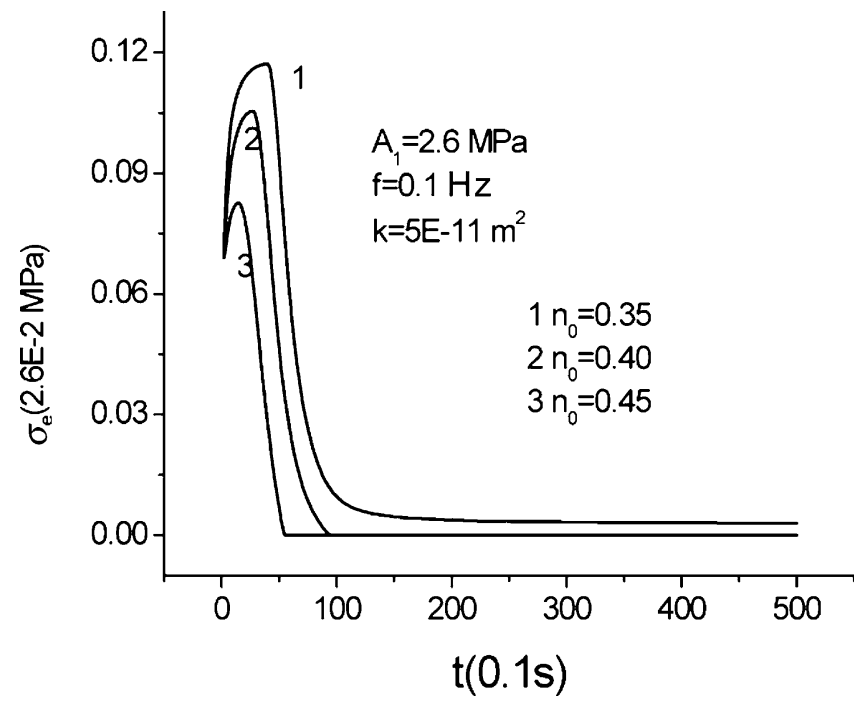

Fig. 7. The influence of the initial porosity to the effective stress. 


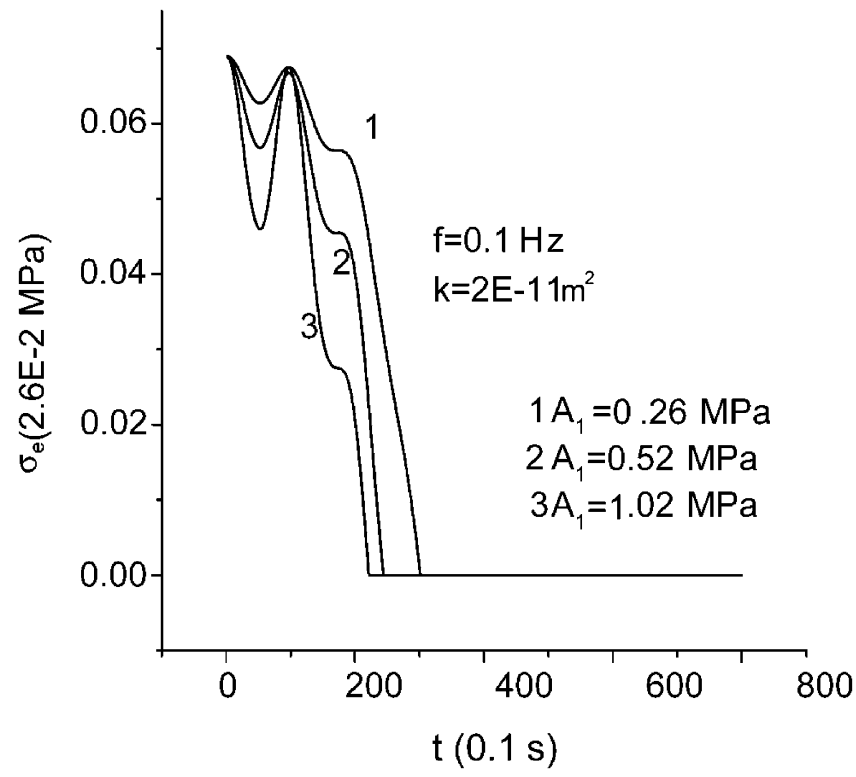

Fig. 8. The influence of the amplitude of loading to the effective stress.

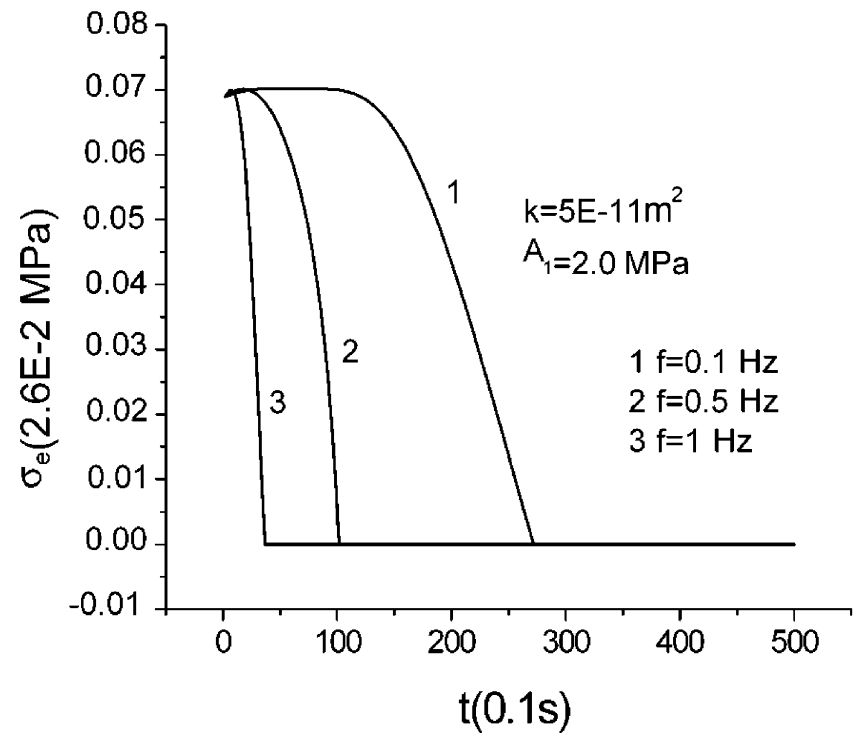

Fig. 9. The influence of the frequency to the effective stress. 


\section{The responses of stresses in vertical direction}

When the permeability at $z=1.0 \mathrm{~m}$ is $30 \%$ smaller than that of other points $\left(n_{0}\right)$, the super pore pressure and the strain will rise sharply and be concentrated on the point with the smallest permeability (Fig. 10, Fig. 11). (The super pore pressure here equals the pore pressure at time $t$ minus the initial pore pressure.) Since pore pressure and the strain rise the fastest, this point will come to the failure state earliest and the fracture in the sand column may occur. It is agree with the main characteristics of the experiments (Peng et al., 2000; Zhang et al., 1999; Fiegel and Kutter, 1994; Kobusho, 1999) and the theoretical analysis (Cheng et al.,, 2000).

Fig. 12 gives the difference of the increment of total stress at any point in the sand layer and that at the upper side (the loading end) with time (total stress at time $t$ minus that at time $t=0:\left.\sigma_{e}\right|_{Z}+\left.p\right|_{Z}-\left.\sigma_{e}\right|_{0}+\left.p\right|_{0}$ ). It is shown that the amplitude increment of total stress changes are obvious, and at the same time, the phase lag is obvious. Fig. 13 gives the relationship between the increment of total stress

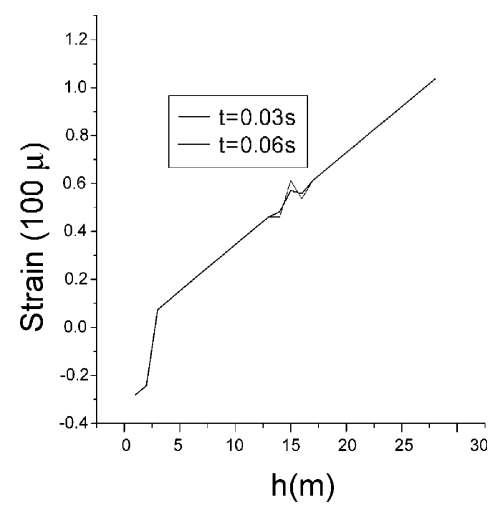

Fig. 10. The changes of strain along depth.

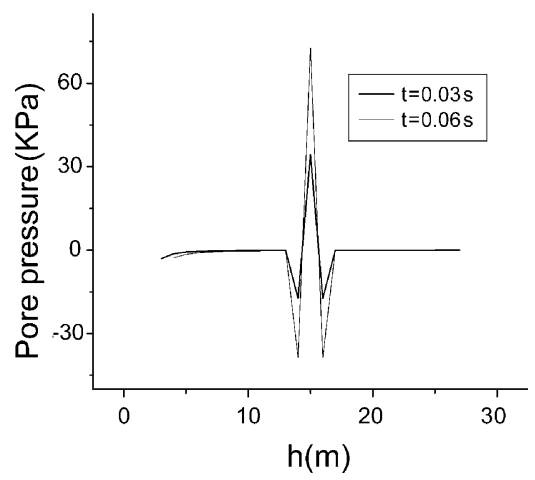

Fig. 11. The changes of pore pressure along depth: the pore pressure here is $p(t)-p_{0}$. 


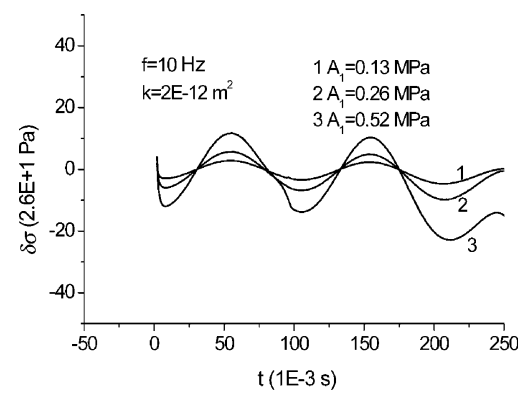

Fig. 12. The minus of total stress of points with that at boundary at different amplitude of loading.

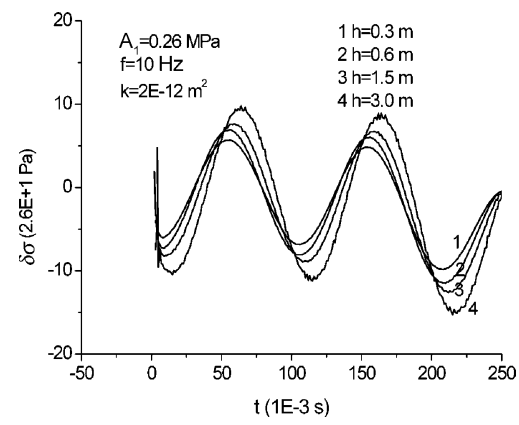

Fig. 13. The minus of total stress at any point in sand with that at the boundary.

with time and the amplitude of loading. It is shown that the larger the amplitude of loading, the larger the changes of total stress in saturated sand. Therefore, only when loading is so small that the inertial of sand may be neglected, can the changes of total stress with depth be neglected.

\section{The influences of factors to expanding of liquefaction thickness}

The influences of factors to the expanding of liquefaction thickness are discussed in this section. These conclusions may be obtained from Figs. 14-19: the smaller the permeability or initial tangent modulus or the larger the initial limit strain or the amplitude or frequency of vibration, the faster the development of liquefaction thickness.

\section{Analysis of affection of factors on liquefaction}

The computing results show that liquefaction appears first near the end of loading, then develops along the depth of sand. Nevertheless, the damping in saturated 


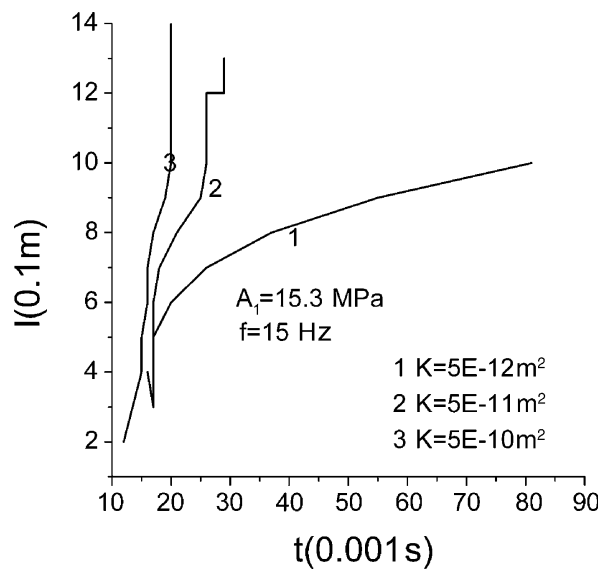

Fig. 14. The influence of permeability.

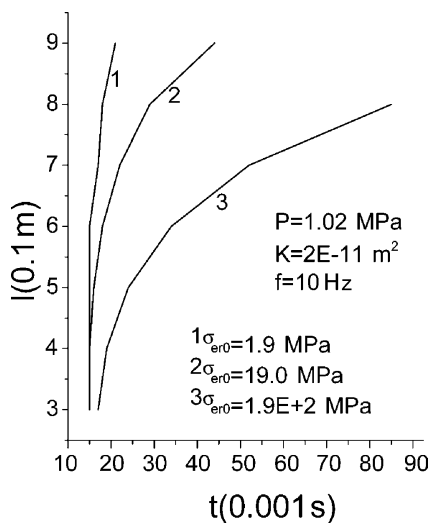

Fig. 15. The influence of initial tangent modulus.

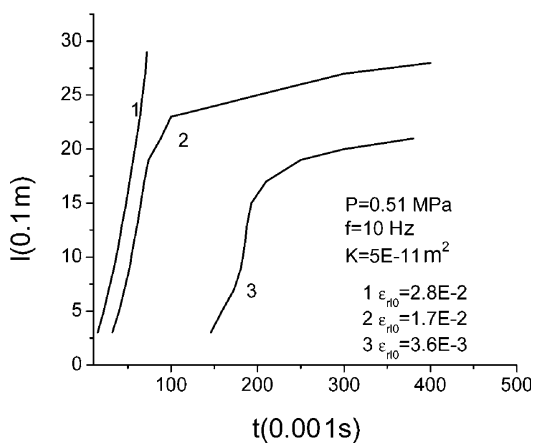

Fig. 16. The influence of initial limit. 


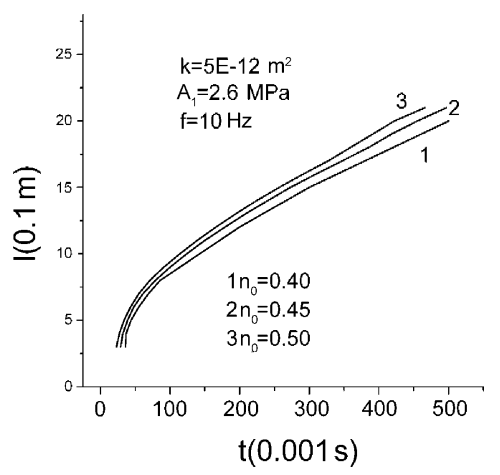

Fig. 17. The influence of initial porosity strain.

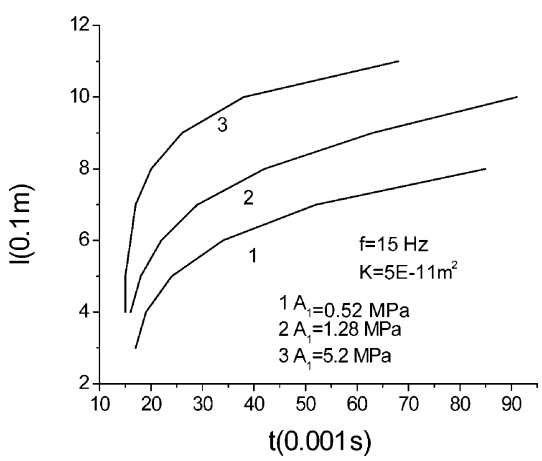

Fig. 18. The influence of amplitude of loading.

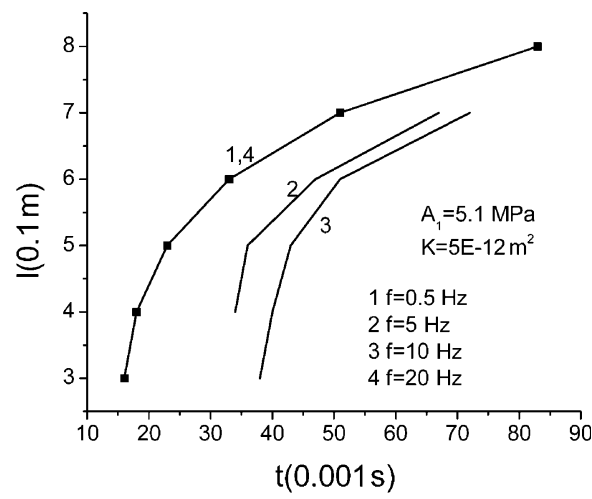

Fig. 19. The influence of frequency of loading. 
sand leads the loading becomes weaker and weaker along the depth so that the developing velocity of liquefaction thickness decreasing gradually till to zero. At this time, the liquefaction thickness is at a maximum.

As we all know, the smaller the permeability, the stronger the force between water and grains, and the pore water is difficult to drain at the same time, so the faster the development of liquefaction thickness is. The smaller the initial tangent modulus or the larger the initial limit strain and the initial porosity, the looser the structure and the smaller the strength of skeleton, so it is easy to liquefy. The larger the amplitude and the frequency of load, the larger the force that saturated sand has to bear and so the faster the development of liquefaction thickness.

\section{Conclusions}

From the above results, we may conclude:

1. The characteristics of the development of effective stress and the liquefaction thickness are as follows: The highly saturated sand may liquefy under water pressure oscillation. The dropping velocity of effective stress rises with the decreasing of permeability or initial tangent modulus or with the rising of amplitude or frequency of loading or initial porosity. The expanding of liquefaction thickness will stop gradually with the increasing of the liquefaction thickness.

2. The total stress and pore pressure are decayed and have phase lag along the depth of sands because of the damping of saturated sand.

3. If the permeability is non-uniform, the pore pressure and the strain will rise sharply and be concentrated on where the smallest permeability is. This is the reason that the fracture occurs in the sand column.

\section{Acknowledgements}

This study is supported by the national natural science foundation project special support to outstanding youth scientist: theoretical foundation of debris flow prediction (No.40025103) and National Natural Science Foundation (No. 10202024).

\section{References}

Biot, M.A., 1956. Theory of propagation of elastic waves in a fluid-saturated porous solid. J. Acoust. Soc. Am. 28, 168-191.

Biot, M.A., 1962. Mechanics of deformation and acoustic propagation in porous media. J. Appl. Phys. 33, 1482-1498.

Cheng, C.-M., Tan, Q., Zhang, J., Peng, F., Yu, S., 2000. Study on the formation of horizontal cracks in saturated sand. Invited paper. In: Proc. XPLOMET 2000, Albuquerque, New Mexico, USA.

Fiegel, G.L., Kutter, B.L., 1994. Liquefaction mechanism for layered soils. J. Geotech. Engrg, ASCE 120 (4), 737-755. 
Finn, W.D.L., Lee, K.W., Martin, G.R., 1977. An effective stress model for liquefaction. J. Geotech. Engrg Div., ASCE 103 (6), 517-533.

Green, A.E., 1970. On flow of fluid through an elastic solid. Acta Mech. 9, 329-340.

Green, A.E., Naghdi, P.M., 1965. A dynamical theory of interacting continua. Int. J. Eng. Sci. 3, 231-241.

Hideo, S., Kita, K., Okamoto, O., 1995. Response of poro-elastoplastic beds to standing waves. Sand Found. 35 (3), 31-42.

Huang, W., 1983. The engineering properties of soils. Hydraulic \& Electrolic Press, Beijing, pp. 86-87 (in Chinese).

Kobusho, T., 1999. Water film in liquefied sand and its effect on lateral spread. J. Geotech. Geoenviron. Engrg, ASCE 125 (10), 817-826.

Liou, C.P., Streeter, V.L., 1977. The numerical model of liquefaction. J. Geotech. Engrg Div., ASCE 103 (GT 4), 589-606.

$\mathrm{Lu}$ X., 1999. The analysis on liquefaction of saturated sand under vertical vibration loading. Dissertation for PhD, Institute of Mechanics, Chinese Academy of Sciences, Beijing.

Nogo, H., Maeno, S., 1987. Pore pressure and effective stresses in a highly saturated sand bed under water pressure variation on its surface. Nat. Dis. Sci. 9 (1), 23-35.

Peng, F., Tan, Q., Cheng, C.-M., 2000. Laboratery study on cracks in saturated sands. Acta Mech. Sin. (Eng. Ser.) 16 (1), 48.

Provest, J.H., 1980. Mechanics of continuous porous media. Int. J. Eng. Sci. 18, 787-800.

Provest, J.H., 1982. Nonlinear transient phenomena in saturated porous media. Comp. Meth. Appl. Mech. Eng 20, 3-8.

Yu, S.B., 1988. Steady development of coal-gas outbursts. Acta Mech. Sin. 20 (2), 97-106 (in Chinese).

Zen, K., Yamazaki, H., 1990. Oscillatory pore pressure and liquefaction in seabed induced by ocean waves. Sand Found. 30 (4), 147-161.

Zienkiewicz, O.C., Shiomi, T., 1984. Dynamic behaviour of saturated porous media; the generalized biot formulation and its numerical solution. Int. J. Num. Anal. Meth. Geomech. 8, 71-96.

Zienkiewicz, O.C., Chang, C.T., Bettess, P., 1980. Drained, undrained, consolidating and dynamic behaviour assumptions in sands: limits of validity. Geotechnique 30, 385-395.

Zhang, J., Meng, X., Tan, Q., Yu, S., 1999. Experimental study on permeability and settlement of saturated sand under impact load. Acta Mech. Sin. 31 (2), 230-237 (in Chinese). 